\title{
Type characterisation and antibiotic susceptibility of Burkholderia (Pseudomonas) cepacia isolates from patients with cystic fibrosis in the United Kingdom and the Republic of Ireland
}

\author{
T. L. PITT, MARY E. KAUFMANN, P. S. PATEL, LOUISE C. A. BENGE ${ }^{\dagger}$, SOPHIE GASKIN and \\ D. M. LIVERMORE*
}

Laboratory of Hospital Infection, Central Public Health Laboratory, 61 Colindale Avenue, London NW9 5HT and

*Department of Medical Microbiology, The London Hospital Medical College, Turner Street, London E1 $2 A D$

\begin{abstract}
The spread of Burkholderia cepacia among cystic fibrosis (CF) patients in the UK prompted an investigation into whether an epidemic strain was responsible. $A$ total of 366 B. cepacia isolates from 178 CF patients in 17 centres was examined by ribotyping and pulsed-field gel electrophoresis (PFGE). Associations were also sought between antibiotic resistance and strain type. More than 50 ribotype patterns were found but one, termed ribotype 1, was identified from 68 patients in eight centres. One centre had a single patient with this type while, in others, most or all patients harboured this organism. Small clusters of apparent cross-colonisation within centres were also evident for some other ribotypes. PFGE confirmed that ribotype 1 isolates were genetically similar. Ribotype 1 isolates were not markedly more resistant to antimicrobial agents than were other isolates, and the MICs of individual antibiotics were no more tightly clustered for ribotype 1 isolates than for others. Most isolates were resistant to ciprofloxacin, amikacin, gentamicin, tobramycin, carbenicillin, cefuroxime, cefotaxime, imipenem, biapenem, chloramphenicol, tetracycline, trimethoprim and sulphamethoxazole, but $\geqslant 77 \%$ were susceptible to ceftazidime, piperacillin, piperacillin/tazobactam and meropenem. We conclude that numerous strains of $B$. cepacia colonise $C F$ patients in the UK and Ireland but that one epidemic strain has spread in at least eight centres. Isolates of this strain appear homogeneous in total genomic profile but very variable in antibiotic susceptibility.
\end{abstract}

\section{Introduction}

Burkholderia (Pseudomonas) cepacia [1] is a pathogen of onions, in which it produces a 'sour and slippery skin' [2]. The species is also an occasional cause of hospital-acquired infection, for example, of bacteraemia in immunocompromised patients who received contaminated infusion fluids [3]. Since 1984, $B$. cepacia has been recognised as an infective agent in cystic fibrosis (CF) patients. Frequencies of isolation in some North American clinics rose from $10 \%$ of patients in the mid-1970s to nearly $40 \% 10$ years later, almost certainly reflecting the spread of an epidemic strain $[4,5]$. Systematic surveys of the prevalence of $B$. cepacia have not been undertaken nationally in the UK but a limited study reported that c. $7 \%$ of patients attending a regional $\mathrm{CF}$ centre harboured the organism [6].

Received 24 April 1995; revised version accepted 23 Aug. 1995.

${ }^{\dagger}$ Deceased. This paper is dedicated to her memory.
There is concern among CF patients and health-care workers about the risk of acquisition and transmission of $B$. cepacia [7]. Recent reports describe exchange of the organism among patients attending the same hospital clinic $[8,9]$ and, most disturbing of all, between CF patients at social gatherings $[10,11]$. More generally, however, the extent of national spread of epidemic strains beyond the CF centres of Edinburgh and Manchester [10] is unknown. Similarly, it is not known whether some strain types of the organism are associated with $\mathrm{CF}$ or, indeed, whether $B$. cepacia isolates from $\mathrm{CF}$ patients have unusual antibiotic resistances or virulence.

The present study describes the results of the typing of $B$. cepacia isolates from patients attending $17 \mathrm{CF}$ centres in the UK and the Republic of Ireland. Typing was performed hierarchically, with ribotyping [12] as the primary means of strain division and with genome macro-restriction analysis by pulsed-field gel electrophoresis (PFGE) [13] as a secondary technique, to discriminate within ribotypes. Antibiotic susceptibility 
tests also were performed and the results were examined for associations between strain types and resistances.

\section{Materials and methods}

\section{Bacterial isolates}

The collection of $B$. cepacia isolates comprised 366 organisms from $178 \mathrm{CF}$ and two non-CF patients in 16 centres in the UK and one in the Republic of Ireland (Table 1). Four further CF isolates from Denmark and eight from the USA were also tested; these were kindly provided by Drs N. Hoiby and T. Stull in Copenhagen and Philadelphia, respectively.

Isolates had been identified as $B$. cepacia by the forwarding laboratories by standard tests. Confirmatory tests were performed as necessary and included oxidative metabolism of glucose, and formation of acid from mannitol, ethanol, dulcitol, lactose and rhamnose in an ammonium salts-based medium [14]. Fifteen isolates failed to utilise glucose or any other sugar but grew well on $B$. cepacia selective medium and had other characteristics consistent with the species such as cytochrome oxidase production and failure to hydrolyse arginine.

\section{Ribotyping}

Chromosomal DNA was extracted from Nutrient Agar (Unipath) cultures by the method of Pitcher et al. [15]. DNA $(5 \mu \mathrm{g})$ was digested with 20 units of restriction endonuclease Eco RI (Gibco BRL, Uxbridge, Middlesex), used according to the supplier's instructions. Restriction fragments were separated by electrophoresis in agarose $0.8 \%$ gels, then transferred to nylon filters under vacuum and hybridised with a cDNA probe to Escherichia coli (16S + 23S) rRNA, as described previously [16]. Biotinylated HindIII digests of lambda phage DNA (Gibco BRL) were included on the gels as mol. wt standards.

\section{Pulsed-field gel electrophoresis}

The general protocol of Grothues et al. [17] was followed. Briefly, isolates were grown overnight on nutrient agar and then suspended in $1 \mathrm{ml}$ of SE buffer (75 mM NaCl, $25 \mathrm{mM}$ EDTA, $\mathrm{pH} \mathrm{7.5)}$ to a turbidity of 25-29 in an ATB 1550 densitometer (bioMérieux, Basingstoke). The cell suspension $(500 \mu \mathrm{l})$ was mixed with an equal volume of low-gelling agarose $2 \%$, and blocks of uniform size were prepared. These were twice treated at $56^{\circ} \mathrm{C}$ overnight with lysis buffer (N-lauroyl sarcosinate $1 \%, 0.5 \mathrm{M}$ EDTA, pH 9.5) containing proteinase $\mathrm{K} 500 \mu \mathrm{g} / \mathrm{ml}$. After three washes with TE buffer (10 mM Tris, $10 \mathrm{mM}$ EDTA, $\mathrm{pH} 7.5$ ), the blocks were stored at $4^{\circ} \mathrm{C}$ in the same buffer. The DNA was then digested with the restriction enzymes $X b a \mathrm{I}$ or SpeI, used according to the supplier's instructions (Gibco BRL).

PFGE was performed in agarose $1.2 \%$ gels in a contour clamped homogeneous electric field apparatus (CHEF DR II, BioRad, Hemel Hempstead, Herts) for $35 \mathrm{~h}$, with start- and end-pulse times of $5 \mathrm{~s}$ and $35 \mathrm{~s}$, respectively. A concatamer ladder of lambda phage DNA was used as a size marker. Gels were stained with ethidium bromide for $1 \mathrm{~h}$ at room temperature, de-stained by shaking in distilled water, and photographed under UV transillumination.

\section{Analysis of banding profiles}

The presence and absence of bands in the ribotyping or CHEF gel lanes were scored as 1 or 0 , respectively, and a pair-wise comparison of similarity for each isolate was made within a single electrophoretic run, by the Dice coefficient [18] with the aid of the computer program MVSP (Kovach Computing Services, Pentraeth, Anglesey).

\section{Susceptibility tests}

Isolates were grown for $48 \mathrm{~h}$ at $30^{\circ} \mathrm{C}$ in $10-\mathrm{ml}$ volumes of nutrient broth and then diluted to $c .3 \times 10^{7} \mathrm{cfu} / \mathrm{ml}$. A multipoint inoculator was used to deliver $0.3-\mu 1$ volumes of the dilutions to IsoSensitest Agar (Unipath) plates containing doubling dilutions of antimicrobial agents, thus giving inocula of $c .10^{4} \mathrm{cfu} / \mathrm{spot}$. The agents tested were: amikacin (Bristol-Myers Squibb, Hounslow, Middlesex); biapenem, piperacillin and piperacillin plus tazobactam (Lederle, Gosport, Hants); carbenicillin (SmithKline Beecham, Brockham Park, Surrey); cefotaxime and gentamicin (Roussel, Uxbridge, Middlesex); ceftazidime and cefuroxime (Glaxo, Greenford, Middlesex); chloramphenicol, sulphamethoxazole, tetracycline and trimethoprim (Sigma); ciprofloxacin (Bayer, Newbury, Berks); imipenem (Merck, Sharp and Dohme, Hoddesdon, Herts); meropenem (Zeneca, Macclesfield, Cheshire) and tobramycin (Eli Lilly, Basingstoke, Hants). Co-trimoxazole was tested as a 5:1 ratio of sulphamethoxazole: trimethoprim. Plates containing either or both of the latter agents were supplemented with lysed horse blood $5 \% \mathrm{v} / \mathrm{v}$.

Pseudomonas aeruginosa NCTC10662 was included on all plates as a control. Results were read after incubation for $48 \mathrm{~h}$ at $30^{\circ} \mathrm{C}$, and minimum inhibitory concentrations (MICs) were taken as the lowest drug concentrations required to prevent growth completely. When MICs for multiple isolates from the same patient were compared, differences of four-fold or greater (i.e., two doubling dilutions) were taken as significant, smaller differences were discounted. 


\section{Results}

\section{Ribotype patterns}

Isolates of $B$. cepacia were received from $178 \mathrm{CF}$ and two non-CF patients in 17 centres (Table 1). Several ribotype patterns were evident among the isolates, each being characterised by four to eight rDNA fragments with molecular sizes between 1.5 and $>23 \mathrm{~kb}$. The spectrum of differences in hybridisation patterns varied from major, with few bands in common, to single-band differences. The reproducibility of band positions between different blots corresponded to $\pm 0.5 \mathrm{~kb}$ for fragments $<9.0 \mathrm{~kb}$ to $\pm 2 \mathrm{~kb}$ for larger fragments. More than 50 ribotype patterns were apparent but, because of the inter-run variation, it was not possible to assign a definitive type number to each of these. Nevertheless, one profile, termed ribotype 1, was widespread. This ribotype was characterised by the presence of seven constant bands accompanied or not by a further band of $c .5 .8 \mathrm{~kb}$ (Fig. 1) and was seen in all the asaccharolytic isolates ( $n=15)$ as well as many typical, saccharolytic organisms. The pattern was identified in isolates from 68 patients in eight centres (Table 1). The proportion of patients with ribotype 1 isolates ranged from one of six in centre A through 13 or 16 in centre $F$, to all of six in centre $Q$. Only one episode of spread of ribotype 1 between centres (centres $\mathrm{F}$ and $\mathrm{D}$ ) by patient transfer was documented. Ribotype 1 was not found among the Irish, Danish or North American CF isolates.

There was great heterogeneity among the isolates that were not of ribotype 1 (Table 1) and many patients harboured unique types. Nevertheless, small clusters of apparent cross-colonisation were identified. For example, six rDNA profiles were found among the nine

Table 1. Summary of ribotyping of $B$. cepacia from different $\mathrm{CF}$ centres

\begin{tabular}{|c|c|c|c|c|}
\hline \multirow[b]{2}{*}{$\begin{array}{l}\text { CF } \\
\text { centre }\end{array}$} & \multicolumn{4}{|c|}{ Number of patients } \\
\hline & total & $\begin{array}{c}\text { with } \\
\text { ribotype } 1\end{array}$ & $\begin{array}{l}\text { with different } \\
\text { profiles }\end{array}$ & $\begin{array}{l}\text { with unique } \\
\text { profiles }\end{array}$ \\
\hline $\mathbf{A}$ & 6 & 1 & 6 & 6 \\
\hline B & 9 & 0 & 6 & 5 \\
\hline $\mathrm{C}$ & 1 & 0 & 1 & 1 \\
\hline D & $1^{*}$ & $1^{*}$ & 1 & 1 \\
\hline $\mathrm{E}$ & 15 & 8 & 6 & 3 \\
\hline F & 16 & 13 & 4 & 3 \\
\hline G & 20 & 15 & 10 & 9 \\
\hline $\mathrm{H}$ & 2 & 0 & 1 & 0 \\
\hline I & 1 & 0 & 1 & 1 \\
\hline $\mathbf{J}$ & 48 & 20 & 10 & 3 \\
\hline $\mathbf{K}$ & 16 & 4 & 4 & 1 \\
\hline L & 1 & 0 & 1 & 1 \\
\hline $\mathbf{M}$ & 5 & 0 & 5 & 4 \\
\hline $\mathbf{N}$ & 2 & 0 & 2 & 2 \\
\hline 0 & $16^{\dagger}$ & 0 & 11 & 8 \\
\hline $\mathbf{P}$ & 15 & 0 & 7 & 3 \\
\hline $\mathrm{Q}$ & 6 & 6 & 1 & 0 \\
\hline Total & 180 & 68 & $\ldots$ & $\ldots$ \\
\hline
\end{tabular}

*Patient transferred from centre $\mathrm{F}$.

${ }^{\dagger}$ Including two non-CF patients.

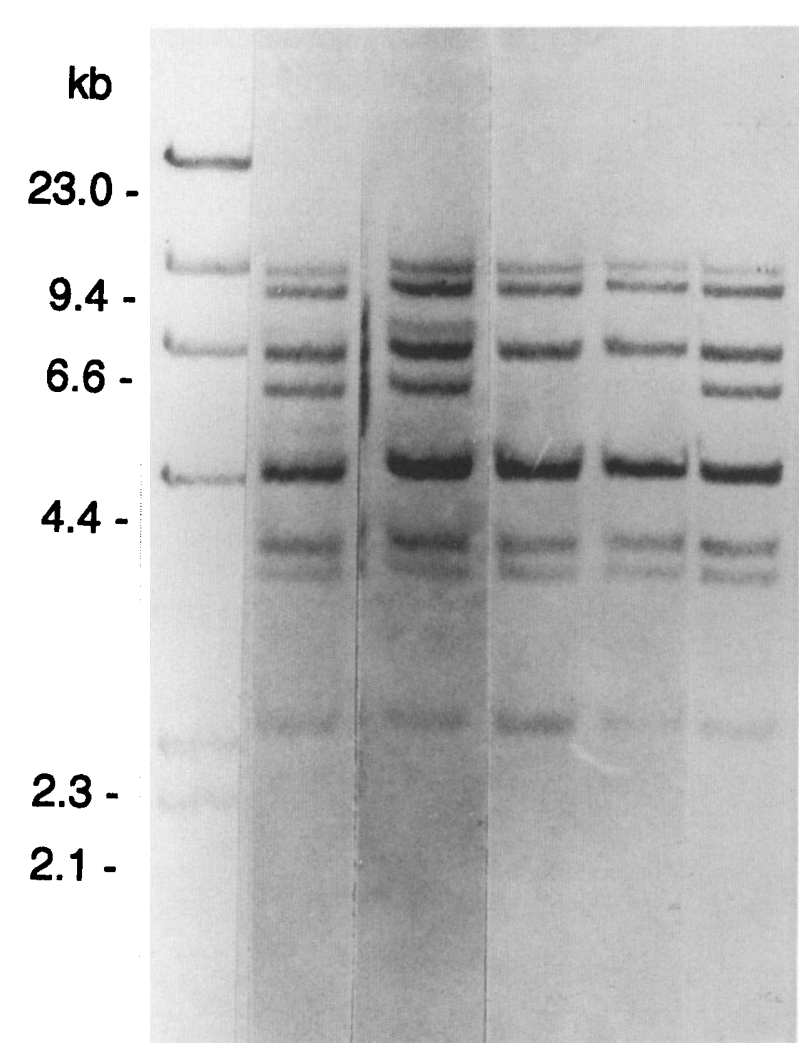

Fig 1. Ribotype pattern 1 of $B$. cepacia from patients attending five different $C F$ centres. Left hand lane: mol. wt markers, biotinylated HindIII digest of lambda phage DNA.

isolates from nine patients in centre B; five of these were unique to single patients but the sixth was shared by four patients. Clusters of apparent cross-colonisation between small numbers of patients were also evident in centre $\mathrm{J}$, where nine different ribotypes, apart from ribotype 1 , were identified in 26 or 47 patients and only three of these types were unique to individual patients.

Table 2. Cross-infection and multiple strain carriage with $B$. cepacia in $\mathrm{CF}$

\begin{tabular}{|c|c|c|c|}
\hline $\begin{array}{l}\mathrm{CF} \\
\text { centre }\end{array}$ & $\begin{array}{l}\text { Number of } \\
\text { sibling groups } \\
\text { with same } \\
\text { ribotype }\end{array}$ & $\begin{array}{l}\text { Number of } \\
\text { non-sibling groups } \\
\text { with same } \\
\text { ribotype }\end{array}$ & $\begin{array}{l}\text { Number of } \\
\text { patients with } \\
>1 \text { ribotype }\end{array}$ \\
\hline B & & 1 & \\
\hline E & 2 & 2 & \\
\hline $\mathbf{F}$ & & 2 & \\
\hline G & 1 & 1 & 3 \\
\hline $\mathbf{H}$ & & 1 & \\
\hline $\mathbf{J}$ & 2 & 7 & 3 \\
\hline $\mathbf{K}$ & & 3 & 1 \\
\hline $\mathbf{M}$ & & 1 & 2 \\
\hline 0 & & 3 & 2 \\
\hline $\mathbf{P}$ & 2 & 3 & \\
\hline
\end{tabular}


B. cepacia was found in seven sibling groups in four centres and, in each of these cases, the members of the pair or group harboured isolates of identical ribotype (Table 2). Among non-siblings, 24 incidents of cross-colonisation were identified involving two-to19 patients and a series of 20 isolates from a single patient over 13 months were indistinguishable from each other. Infection with strains of two different ribotypes was found in only 11 patients in five centres.

\section{Homogeneity of ribotype 1}

A variety of DNA macro-restriction profiles was revealed by PFGE for isolates of different ribotypes but those of ribotype 1 from different centres gave closely related profiles. This is illustrated in Fig. 2 which shows that the profiles of nine isolates from eight patients (lanes 1-6, and 8-10), including two sibling pairs ( 2 and 3,4 and 5 ), differed by three or
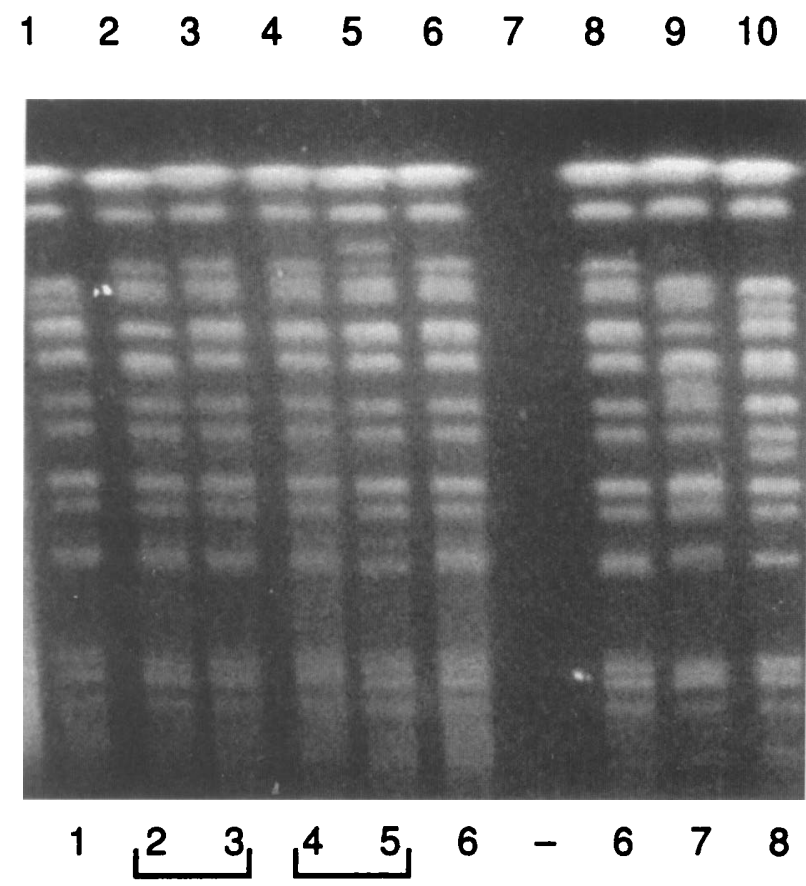

Fig. 2 PFGE patterns of ribotype 1 isolates of $B$. cepacia from $8 \mathrm{CF}$ patients. Patients 2 and 3 , and 4 and 5 are siblings. fewer bands, corresponding to Dice coefficients of $>90 \%$.

Only four PFGE patterns, differing by three bands or fewer, could be distinguished among all ribotype 1 isolates throughout the UK, and one of these patterns was exclusively associated with the 15 asaccharolytic isolates from two centres. Autodegradation of chromosomal DNA was rare but, when it occurred (Fig. 2, lane 7), no DNA bands were visible after electrophoresis.

\section{Susceptibility tests}

Susceptibility tests were performed on 102 ribotype 1 and 167 other isolates and the MICs found are shown as box plots in Fig. 3. This mode of display is valid in the present study as all the MIC distributions were unimodal $[19,20]$. The MIC50s of most antimicrobial agents for the ribotype 1 isolates were one doubling dilution higher than for isolates of other ribotypes. MIC10, MIC25, MIC75 and MIC90 values also were raised for the ribotype 1 isolates, and the MIC50s of piperacillin/tazobactam, trimethoprim and co-trimoxazole were 4-8-fold higher for these isolates than for those of other ribotypes. Nevertheless, there was substantial overlap between the MICs for ribotype 1 isolates and those for other ribotypes with all the antimicrobial agents. Moreover, and critically, the MICs of individual antimicrobial agents for ribotype 1 isolates were no more tightly clustered than were those for the isolates of diverse ribotypes. MIC ranges and MIC50s for asaccharolytic and saccharolytic ribotype 1 isolates were very similar.

Among the 269 isolates for which MICs were determined, 153 were from patients $(n=56)$ who contributed more than one isolate. Fifty-three patients yielding multiple isolates had organisms of a single ribotype and only three had isolates of more than one ribotype. Normally multiple isolates of the same ribotype from the same patient would be excluded from antibiotic resistance analysis, but this was not done here as many apparent replicates differed greatly in susceptibility profile (Fig. 4 and Table 3 ). In some cases, e.g., patient 1 in Table 3, one isolate was more

Table 3. MIC variation between pairs of isolates of the same type of B. cepacia from two CF patients

\begin{tabular}{|c|c|c|c|c|c|c|c|c|c|c|}
\hline \multirow{2}{*}{$\begin{array}{c}\text { Patient } \\
\text { no. }\end{array}$} & \multirow{2}{*}{$\begin{array}{c}\text { Isolate } \\
\text { no. }\end{array}$} & \multicolumn{9}{|c|}{$\mathrm{MIC}(\mathrm{mg} / \mathrm{L})$} \\
\hline & & Cip & Pip & Pip/Taz & $\mathrm{Caz}$ & Cxm & $\mathrm{Ctx}$ & $\operatorname{Imp}$ & Mem & $\mathrm{Bia}$ \\
\hline \multirow[t]{2}{*}{1} & 1 & 4 & 2 & 2 & 4 & 16 & 4 & - & 2 & 2 \\
\hline & 2 & 32 & 256 & 256 & 64 & 128 & 128 & - & 16 & 32 \\
\hline \multirow[t]{2}{*}{2} & 1 & 16 & 8 & 8 & 8 & - & 32 & 128 & 16 & 32 \\
\hline & 2 & 128 & 64 & 32 & 64 & - & 8 & 16 & 1 & 8 \\
\hline
\end{tabular}

Cip, ciprofloxacin; Pip, piperacillin; Pip-Taz, piperacillin + tazobactam $4 \mathrm{mg} / \mathrm{L}$; Caz, ceftazidime; Cxm, cefuroxime; Ctx, cefotaxime; Imp, imipenem; Mem, meropenem; Bia, biapenem.

MIC data are not shown where the difference between the two isolates was one dilution or less: this was the case for amikacin, gentamicin, tobramycin, carbenicillin, imipenem, chloramphenicol, tetracycline, trimethoprim, sulphamethoxazole and co-trimoxazole against the isolates from patient 1 and for amikacin, gentamicin, tobramycin, carbenicillin, cefuroxime, tetracycline, trimethoprim, sulphamethoxazole and cotrimoxazole against those from patient 2. 


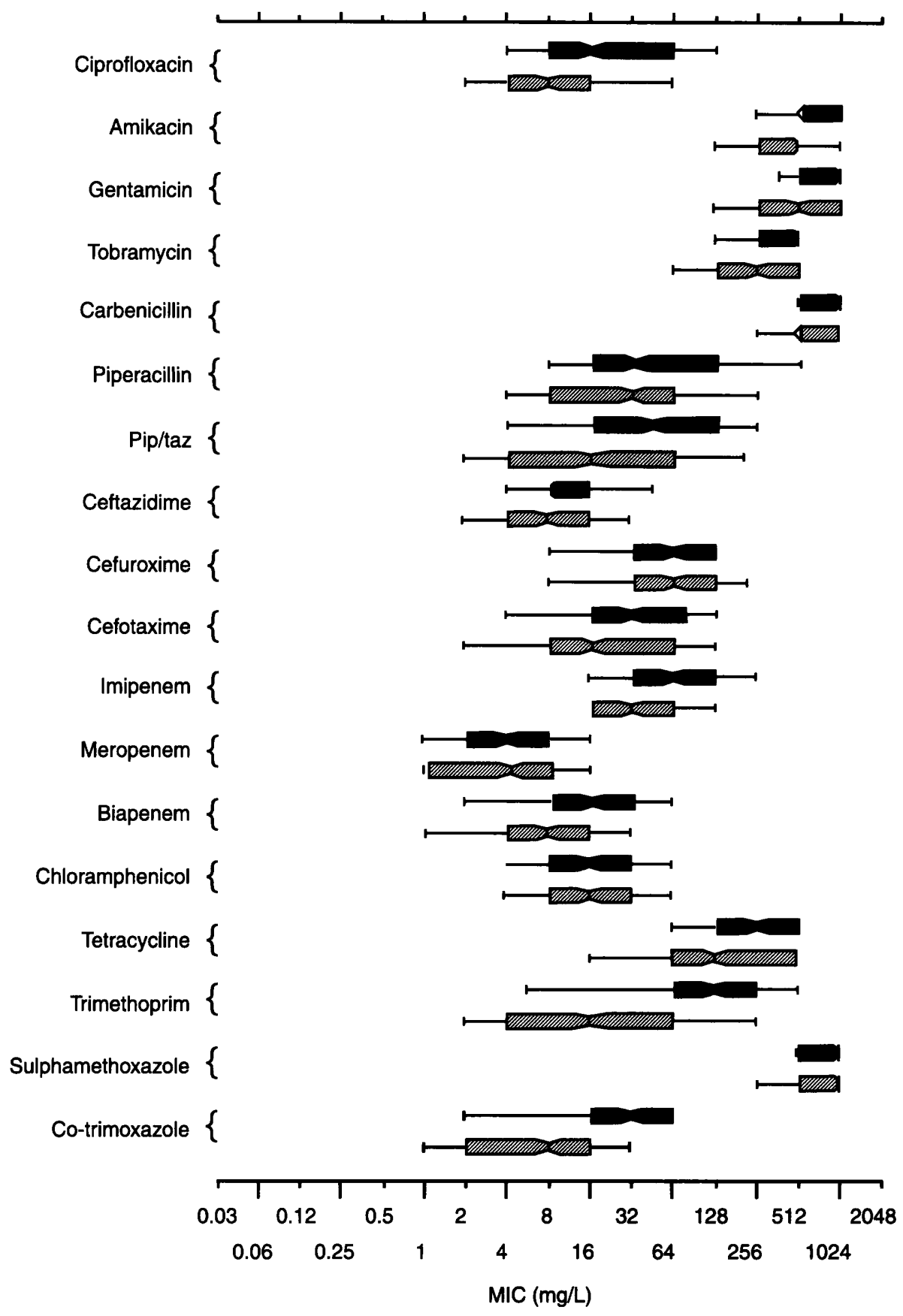

Fig. 3. Box plot of susceptibility distributions for ribotype $1(\square)$ and other $(\square) B$. cepacia isolates. The waist on the shaded block is the MIC50, the ends of the block show the MIC25 and MIC75 and the ends of the bars indicate the MIC10 and MIC90.

resistant to a range of $\beta$-lactams than was the other of the same ribotype and PFGE profile, and had similar resistance to other agents. In others, exemplified by patient 2 in the same table, the MICs of structurally diverse antimicrobial agents were variously raised or lowered between two isolates of the same type from the same patient, without any apparent consistency.

\section{Discussion}

The question as to whether $B$. cepacia is transmitted among CF patients in and out of hospitals has been debated widely $[10,11,21,22]$. Ribotyping of isolates by LiPuma and colleagues $[12,21]$ showed that patients within the same CF centre often harboured strains of the same type but that different strains predominated in different centres. However, the presence of distinct strains, defined by PFGE, in each patient at a single CF centre led Steinbach et al. [22] to suggest that ribotyping was not sufficiently discriminatory for the typing of patient isolates. On the other hand, Johnson et al. [23] concluded that ribotyping was a useful tool for the investigation of outbreaks but that it lacked the stability necessary to define the population structure of the species as a whole. The results from the use of the 


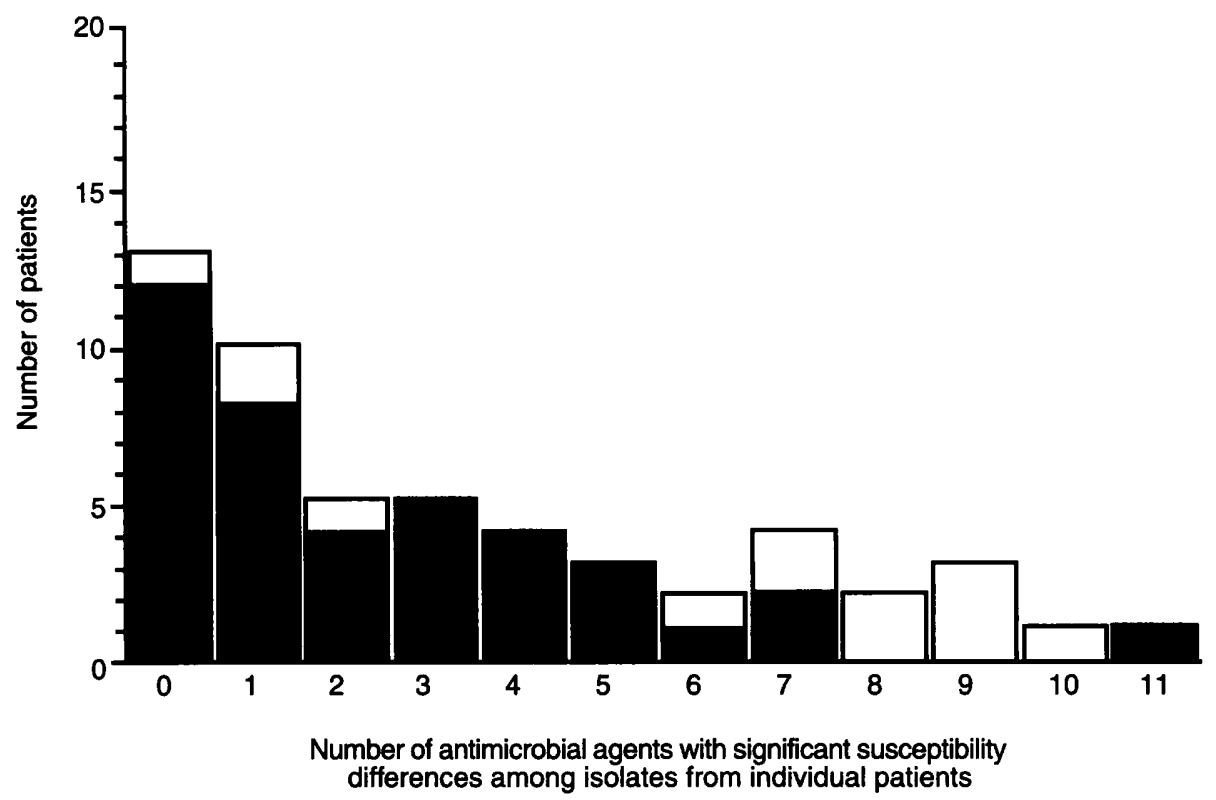

Fig. 4. Susceptibility variation among multiple isolates of $B$. cepacia of the same ribotype from individual patients. Data are shown for 40 patients from whom two isolates were compared ( $\boldsymbol{\square})$, and for 13 patients from whom more than two isolates (3-10) were tested ( $\square$ ). A significant difference was defined as $>$ four-fold. Eighteen antimicrobial agents were considered in total.

two methods together suggest that their interpretation is best achieved if they are considered in a hierarchical fashion with ribotyping forming the primary division of the species. Isolates of the same ribotyping can then be subdivided by PFGE to provide a definitive strain profile.

The present study aimed to identify the types of B. cepacia prevalent among British and Irish $\mathrm{CF}$ patients to determine whether particular strains predominated, and whether the inter-regional spread of a strain first demonstrated by Govan et al. [10] had extended to other centres. At least 50 different ribotypes were identified among the 366 isolates studied from the 180 patients, but variation between gels in the precise distances migrated by DNA fragments precluded allocation of ribotype numbers. Nevertheless, a common ribotype pattern differing by a single band between isolates was evident and was termed ribotype 1 to distinguish it from other patterns. The homogeneity of ribotype 1 isolates in terms of chromosomal DNA macro-restriction profile, first reported from an outbreak among $\mathrm{CF}$ patients in Birmingham UK [24], was confirmed by this study which further demonstrated the distribution of isolates of the ribotype across centres. Johnson et al. [23] found, by multilocus enzyme electrophoresis, that isolates corresponding to the UK ribotype 1 strain fell into the same clonal group (ET 12) as those from the first documented outbreak of B. cepacia in CF patients in Ontario, Canada [4], and suggested that this strain was transmitted to UK patients attending summer camps in Ontario. PFGE profiles of isolates of ribotype 1 displayed remarkable similarity, underlining their genetic relatedness. However, the identity of asaccharolytic isolates is unclear. The fact that they were ribotype 1 and gave PFGE profiles highly similar to saccharolytic isolates of the same ribotype suggests that they are most likely variants of the latter. Simpson et al. [25] described CF isolates which, by their biochemical characteristics and fatty acid content, more closely resembled $B$. gladioli than $B$. cepacia. These gave weak or negative reactions in maltose and lactose oxidation tests but they were not termed asaccharolytic. It is not certain that the asaccharolytic isolates examined here were $B$. cepacia or $B$. gladioli, but a plausible view is that the asaccharolytic strains are variants lacking a pivotal enzyme in glycolysis. Unlike Simpson et al. [25] substantial differences in antibiotic susceptibility between saccharolytic $B$. cepacia and asaccharolytic strains were not found.

Lack of information means that it was not possible to relate the clinical condition of patients to the presence or absence of the ribotype 1 organism, but it was clear from discussions with the responsible physicians that the clinical presentation of carriers varied from asymptomatic to severe respiratory infection. Thus, the ribotype 1 strain is not overly virulent for CF patients but does seem to be highly transmissible between patients and centres, having been found in nearly one-third of the present patients. This finding confirms the view of Govan et al. [10] that despite the fact that many Edinburgh patients were colonised with this strain and had raised antibody levels to the strain, prognostic statements could not be made as the index case of their outbreak remained alive while some others died.

The factors that influence the acquisition and persistence of a strain of $B$. cepacia by patients are 
unknown but adhesive ability, cell-wall structures, and production of virulence factors may be significant [26]. The adherence property is probably strain variable but ribotype 1 isolates from CF patients in the Edinburgh outbreak $[8,10]$ were six-fold more adherent to mucin than other strains [27].

MIC tests underscored the considerable resistance of the species and showed that ribotype 1 isolates were not markedly more resistant than other ribotypes to most antimicrobial agents. The results also showed that MICs of individual agents varied widely and that this scatter of MICs was typically almost as wide among ribotype 1 isolates as for those of all other ribotypes. This observation seemingly challenges the view that the ribotype 1 isolates are a tight cluster, but the apparent contradiction may be explained if the organism can readily alter its antibiogram. Such a view is plausible in the light of the finding of Scordilis et al. [28] that migration of insertion sequences within the $B$. cepacia chromosome can affect the expression of genes that modulate antibiotic resistance. Regulation by this mechanism might also explain why isolates of identical ribotype, but differing radically in antibiogram, were often isolated from the same patient (Table 3). This variability in resistance has also been observed by others in serial isolates from single and multiple patients $[25,29,30]$. Simple point mutations might also explain some accumulation of resistance, for example, the differences in resistances to $\beta$-lactams between the two isolates from patient 1 (Table 3 ); but seems unlikely as a source of the more diverse changes between the two isolates from patient 2 .

No great optimism can be raised about the anti- $B$. cepacia activity of any antimicrobial agent tested. Over $58 \%$ of the isolates, whether of ribotype 1 or not, were resistant to each of the following agents at the 'high' breakpoints advocated by the British Society for Antimicrobial Chemotherapy (BSAC) [31]: ciprofloxacin $4 \mathrm{mg} / \mathrm{L}$, amikacin $16 \mathrm{mg} / \mathrm{L}$, gentamicin $4 \mathrm{mg} / \mathrm{L}$, tobramycin $1 \mathrm{mg} / \mathrm{L}$, carbenicillin $128 \mathrm{mg} / \mathrm{L}$, cefuroxime $16 \mathrm{mg} / \mathrm{L}$, imipenem $8 \mathrm{mg} / \mathrm{L}$, biapenem $8 \mathrm{mg} / \mathrm{L}$, chloramphenicol $8 \mathrm{mg} / \mathrm{L}$, tetracycline $1 \mathrm{mg} / \mathrm{L}$, trimethoprim $2 \mathrm{mg} / \mathrm{L}$ and sulphamethoxazole $128 \mathrm{mg} / \mathrm{L}$. Cefotaxime too can also be dismissed; most of the isolates were resistant at the NCCLS breakpoint of $16 \mathrm{mg} / \mathrm{L}$ [32] let alone at the BSAC breakpoint of $1 \mathrm{mg} / \mathrm{L}$. The only agents with any promise were piperacillin, piperacillin-tazobactam, ceftazidime and meropenem. Over $77 \%$ of the isolates were susceptible to piperacillin at the BSAC's high breakpoint of $64 \mathrm{mg} / \mathrm{L}$, and a slightly greater proportion were susceptible when tazobactam was present. In the case of ceftazidime, fewer than $10 \%$ of the isolates were susceptible at the BSAC breakpoint of $2 \mathrm{mg} / \mathrm{L}$, but $85 \%$ were susceptible at the NCCLS breakpoint of $16 \mathrm{mg} / \mathrm{L}$. With meropenem, $80 \%$ of the isolates were susceptible at the breakpoint of $8 \mathrm{mg} / \mathrm{L}$.
These frequencies of susceptibilities appear tolerable, but the breakpoints upon which they are based are optimistic when compared with the peak drug levels attained in bronchial secretions, i.e., for piperacillin $29.3 \mathrm{mg} / \mathrm{L}$ [33], and ceftazidime $0.7-9.8 \mathrm{mg} / \mathrm{L}$ [34]. Fewer than half the $B$. cepacia isolates were susceptible to these drugs at these levels.

Piperacillin and ceftazidime have been used against B. cepacia in CF patients, but with very mixed success, and with some emergence of resistance during therapy [35]. Lewin et al. [36] also showed that meropenem was among the most active compounds against $B$. cepacia - the MIC90 for 109 nonCF isolates was $4 \mathrm{mg} / \mathrm{L}$ and for $C F$ isolates, $16 \mathrm{mg} / \mathrm{L}$. The effect of cultural conditions on the susceptibility of $B$. cepacia to several $\beta$-lactam compounds was recently investigated by Corkill et al. [37] who showed that incubation of strains in $\mathrm{CO}_{2} \quad 5 \%$ decreased the activity of piperacillin-tazbactam and ceftazidime. Although these conditions were unusual for susceptibility testing of this organism, they may reflect those in the CF lung and provide a possible explanation, for these two antibiotics, why in-vitro susceptibility is often not reflected by in-vivo response. In conclusion, there are numerous strains of $B$. cepacia colonising CF patients across Britain but a single strain has spread between at least eight $\mathrm{CF}$ regional centres. Isolates of this strain are homogeneous in genomic profile but very variable in antibiotic susceptibility and saccharolytic activity.

This work was supported by the Cystic Fibrosis Trust of Great Britain (Grant 353). We thank Drs N. Hoiby and T. Stull for providing isolates from their respective countries, and the staff of the Gramnegative Unit, Central Public Health Laboratory for their assistance with the survey.

\section{References}

1. Yabuuchi E, Kosako $\mathrm{Y}$, Oyaizu $\mathrm{H}$ et al. Proposal of Burkholderia gen.nov. and transfer of seven species of the genus Pseudomonas homology group II to the new genus, with the type species Burkholderia cepacia (Palleroni and Holmes 1981) comb. nov. Microbiol Immunol 1992; 36: 1251-1275.

2. Burkholder WH. Sour skin: a bacterial rot of onion bulbs. Phytopathol 1950; 40: 115-117.

3. Martone WJ, Tablan OC, Jarvis WR. The epidemiology of nosocomial epidemic Pseudomonas cepacia infections. Eur $J$ Epidemiol 1987; 3: 222-232.

4. Isles A, Maclusky I, Corey $M$ et al. Pseudomonas cepacia infection in cystic fibrosis: an emerging problem. $J$ Pediatr 1984; 104: 206-210.

5. Thomassen MJ, Demko CA, Klinger JD, Stern RC. Pseudomonas cepacia colonization among patients with cystic fibrosis. A new opportunist. Am Rev Respir Dis 1985; 131: 791-796.

6. Gladman G, Connor PJ, Williams RF, David TJ. Controlled study of Pseudomonas cepacia and Pseudomonas maltophilia in cystic fibrosis. Arch Dis Child 1992; 67: 192-195.

7. Walters S, Smith EG. Pseudomonas cepacia in cystic fibrosis: transmissibility and its implications. Lancet 1993; 342: 3-4.

8. Nelson JW, Doherty CJ, Brown PH, Greening AP, Kaufmann ME, Govan JRW. Pseudomonas cepacia in inpatients with cystic fibrosis. Lancet 1991; 338: 1525.

9. Millar-Jones L, Paull A, Saunders Z, Goodchild MC. Transmission of Pseudomonas cepacia among cystic fibrosis patients. Lancet 1992; 340: 491. 
10. Govan JRW, Brown PH, Maddison $\mathrm{J}$ et al. Evidence for transmission of Pseudomonas cepacia by social contact in cystic fibrosis. Lancet 1993; 342: 15-19.

11. Corkill JE, Sisson PR, Smyth A et al. Application of pyrolysis mass spectroscopy and SDS-PAGE in the study of the epidemiology of Pseudomonas cepacia in cystic fibrosis. $J$ Med Microbiol 1994; 41: 106-111.

12. LiPuma JJ, Mortensen JE, Dasen SE et al. Ribotype analysis of Pseudomonas cepacia from cystic fibrosis treatment centers. $J$ Pediatr 1988; 113: 859-863.

13. Anderson DJ, Kuhns JS, Vasil ML, Gerding DN, Janoff EN. DNA fingerprinting by pulsed field electrophoresis and ribotyping to distinguish Pseudomonas cepacia isolates from a nosocomial outbreak. J Clin Microbiol 1991; 29: 648-649.

14. Barrow GI, Feltham RKA (eds). Cowan and Steel's Manual for the identification of medical bacteria, 3rd edn. Cambridge, Cambridge University Press. 1993: 30-31.

15. Pitcher DG, Saunders NA, Owen RJ. Rapid extraction of bacterial genomic DNA with guanidium thiocyanate. Lett Appl Microbiol 1989; 8: 151-156.

16. Garaizar J, Kaufmann ME, Pitt TL. Comparison of ribotyping with conventional methods for the type identification of Enterobacter cloacae. J Clin Microbiol 1991; 29: 1303-1307.

17. Grothues D, Koopmann U, von der Hardt H, Tümmler B. Genome fingerprinting of Pseudomonas aeruginosa indicates colonization of cystic fibrosis siblings with closely related strains. J Clin Microbiol 1988; 26: 1973-1977.

18. Dice LR. Measures of the amount of ecologic association between species. Ecology 1945; 26: 297-302.

19. Donnelly JP. Limitations of box-plots in summarizing MIC data. J Antimicrob Chemother 1994; 33: 1251.

20. Shannon K. Limitations of box-plots in summarizing MIC data: reply. J Antimicrob Chemother 1994; 33: 1252.

21. LiPuma J, Dasen SE, Neilson DW, Stern RC, Stull TL. Personto-person transmission of Pseudomonas cepacia between patients with cystic fibrosis. Lancet 1990; 336: 1094-1096.

22. Steinbach S, Sun L, Jiang RZ et al. Transmissibility of Pseudomonas cepacia infection in clinic patients and lungtransplant recipients with cystic fibrosis. $N$ Engl J Med 1994; 331: $981-987$.

23. Johnson WM, Tyler SD, Rozee KR. Linkage analysis of geographic and clinical clusters in Pseudomonas cepacia infections by multilocus enzyme electrophoresis and ribotyping. J Clin Microbiol 1994; 32: 924-930.

24. Smith DL, Gumery LB, Smith EG, Stableforth DE, Kaufmann ME, Pitt TL. Epidemic of Pseudomonas cepacia in an adult cystic fibrosis: evidence of person-to-person transmission. $J$ Clin Microbiol 1993; 31: 3017-3022.

25. Simpson IN, Finlay J, Winstanley DJ et al. Multi-resistance isolates possessing characteristics of both Burkholderia
(Pseudomonas) cepacia and Burkholderia gladioli from patients with cystic fibrosis. $J$ Antimicrob Chemother 1994; 34: 353-361.

26. Nelson JW, Butler SL, Krieg D, Govan JRW. Virulence factors of Burkholderia cepacia. FEMS Immunol Med Microbiol 1994; 8: 89-98.

27. Butler SL, Nelson JW, Govan JRW. Cell surface characteristics of Pseudomonas cepacia isolates from patients with cystic fibrosis. XI International CF Congress, Dublin 1992. Abstract TP8.

28. Scordilis GL, Ree H, Lessie TG. Identification of transposable elements which activate gene expression in Pseudomonas cepacia. J Bacteriol 1987; 169: 8-13.

29. Yohalem DS, Lorbeer JW. Multilocus isoenzyme diversity among strains of Pseudomonas cepacia isolated from decayed onions, soils and clinical sources. System Appl Microbiol 1994; 17: $116-124$.

30. LiPuma JJ, Fisher MC, Dasen SE, Mortensen JE, Stull TL. Ribotype stability of serial pulmonary isolates of Pseudomonas cepacia. J Infect Dis 1991; 164: 133-136.

31. Working Party on Antibiotic Sensitivity Testing of the British Society for Antimicrobial Chemotherapy. A guide to sensitivity testing. J Antimicrob Chemother 1991; 27 Suppl D: 1-50.

32. National Committee for Clinical Laboratory Standards. Methods for dilution antimicrobial susceptibility tests for bacteria that grow aerobically, 3rd edn. Document LM7-A3 1993; 13 No. 25. Villanova, PA, National Committee for Clinical Laboratory Standards. 1993.

33. Muller-Serieys C, De Larminat V, Monteil H, BergogneBerezin E, Jehl $H$. Bronchial penetration of piperacillintazobactam (Pip-tz) in intensive care patients: a multiple dose study. Program and Abstracts of the 33rd Interscience Conference on Antimicrobial Agents and Chemotherapy 1993; Abstract no. 253.

34. Strandvik B, Malmborg A-S, Alfredson H, Ericsson A. Clinical results and pharmacokinetics of ceftazidime treatment in patients with cystic fibrosis. J Antimicrob Chemother 1983; 12 Suppl A: 283-287.

35. Gold R, Jin E, Levison A, Isles A, Fleming PC. Ceftazidime alone and in combination in patients with cystic fibrosis: lack of efficacy in treatment of severe respiratory infections caused by Pseudomonas cepacia. J Antimicrob Chemother 1983; 12 Suppl A: 331-336.

36. Lewin $\mathrm{C}$, Doherty $\mathrm{C}$, Govan J. In vitro activities of meropenem, PD 127391, PD 131628, ceftazidime, chloramphenicol, co-trimaxazole, and ciprofloxacin against Pseudomonas cepacia. Antimicrob Agents Chemother 1993; 37: 123-125.

37. Corkill JE, Deveney J, Pratt $\mathrm{J}$ et al. Effect of $\mathrm{pH}$ and $\mathrm{CO}_{2}$ on in vitro susceptibility of Pseudomonas cepacia to $\beta$-lactams. Pediatr Res 1994; 35: 299-302. 